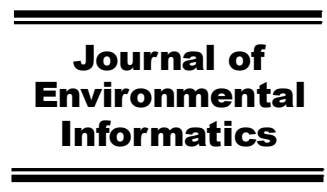

www.iseis.org/jei

\title{
Incorporation of Optimal Limited Ecological Curves into the Operation Chart of Cascade Hydropower Systems to Alleviate Ecological Damages in Hydrological Extremes
}

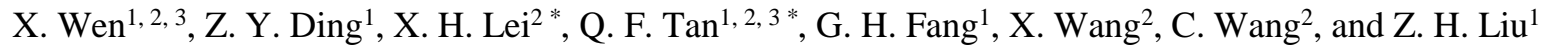 \\ ${ }^{I}$ College of water conservancy and hydropower engineering, Hohai University, Nanjing 210098, China \\ ${ }^{2}$ State key laboratory of simulation and regulation of water cycle in river basin, China Institute of Water Resources and Hydropower Research, \\ Beijing 100038, China \\ ${ }^{3}$ State key laboratory of hydraulics and mountain river engineering, Sichuan University, Chengdu 610065, China
}

Received 13 January 2019; revised 13 July 2019; accepted 27 October 2019; published online 30 June 2020

\begin{abstract}
Most ecological operation charts of hydropower stations have focused on the average ecological benefits over a long period of time, while the possible ecological damage caused by flood or drought is often overlooked or averaged out. This study proposed a new hydropower-ecological operation chart of cascade hydropower stations, in which limited ecological curves were introduced and optimized to alleviate the negative impacts caused by drought or flood events on fish habitat and to maintain the long-term average habitat quality without reducing the power generation. The optimal ecological discharge range at a given ecological conservation target was determined from the weighted usable area-discharge curve using the physical habitat simulation model, and then the upper and lower limited ecological curves were obtained by reverse calculation, which together with the conventional operation chart (COC) formed the ecological operation chart (EOC). The limited ecological curves were further optimized with the goal of reducing the ecological damage frequency in wet and dry extremes, and then incorporated into COC to form the optimized ecological operation chart (OEOC). A case study was performed with Jasajiang (JS) and Madushan (MDS) cascade reservoirs on the Yuan River in southwestern China. The results show that the EOC that takes into account the ecological benefits can reduce the ecological damage frequency compared to the COC, but potentially at the expense of the overall ecological benefit. However, further optimization of limited ecological curves in OEOC makes it possible to obtain higher short-term ecological benefit and lower ecological damage frequency with the loss of lower overall ecological benefit. Specifically, OEOC is helpful to reduce the ecological damage frequency and improve the power generation and overall ecological benefit at an ecological target of $60 \sim 80 \%$. Notably, at an ecological target of $80 \%$, OEOC results in a $4.1 \%$ increase in power generation and a $11.25 \%$ decrease in ecological damage frequency for JS-MDS cascade reservoirs compared with that of COC, respectively.
\end{abstract}

Keywords: Ecological damage, ecological streamflow, hydrological extremes, limited ecological curve, operation chart optimization

\section{Introduction}

The operation chart gives a graphical representation of reservoir operation rules, making it the most intuitive and popular tool for controlling the reservoir operation in many countries. However, the application of conventional operation chart (COC) to multipurpose reservoirs may be limited as it often considers only power generation or water supply but does not take account of the potential impacts on the river ecosystems. Most previous studies have focused on the average ecological benefits over a long period of time, while the possible ecological damage caused by flood or drought during a certain period is often overlooked or averaged out. Actually, these hydrolog-

${ }^{*}$ Corresponding author. Tel.: +86 1068781980 ; fax: +86 2568785657.

E-mail address: 1xh@iwhr.com (X. H. Lei).

${ }^{*}$ Corresponding author. Tel.: +86 25 83786599; fax: +86 2583786599 .

E-mail address: Qiaofengtan@126.com (Q. F. Tan).

ISSN: 1726-2135 print/1684-8799 online

() 2020 ISEIS All rights reserved. doi:10.3808/jei.202000436 ical extremes may cause severe irreversible damages to river ecosystems (He et al., 2014; Tan et al., 2017; Wang 2017). Here, attempts have been made to balance power generation, long- and short-term ecological benefits in operation of cascade reservoirs.

Operation chart is usually derived by the reverse calculation method (Cheng et al., 2010). However, this is by no means a simple task and it needs to be modified manually. Considerable attempts have been made to optimize operation charts, but most previous studies have focused on water supply, power generation and flood control, with less attention to potential ecological impacts. Table 1 summarizes recent advancement in ecological operation and operation chart optimization of reservoirs.

Most previous studies on ecological operation of hydropower stations have focused on the average ecological benefit over a long period of time, while the possible ecological damage caused by flood or drought during a certain period is often overlooked or averaged out. Accordingly, the objective of these 
Table 1. Sensitivity Analysis for the Parameters

\begin{tabular}{|c|c|c|c|}
\hline $\begin{array}{l}\text { Authors } \\
\text { (year) }\end{array}$ & Optimization targets/objectives & $\begin{array}{l}\text { Ecological requirements } \\
\text { quantification and modeling } \\
\text { techniques }\end{array}$ & Key conclusions \\
\hline $\begin{array}{l}\text { Zahraie } \\
\text { and } \\
\text { Hossein } \\
\text { (2009) }\end{array}$ & $\begin{array}{l}\text { Reservoir operation policies/Minimize } \\
\text { the total loss in the supply of water or } \\
\text { the waste of water resources }\end{array}$ & None & $\begin{array}{l}\text { Fuzzy linear regression is used to develop the } \\
\text { optimal operation policies, which are shown } \\
\text { to be helpful in balancing the variations in } \\
\text { monthly releases with respect to the range of } \\
\text { probable demands in each month. }\end{array}$ \\
\hline $\begin{array}{l}\text { Jiang et al. } \\
(2014)\end{array}$ & $\begin{array}{l}\text { Total output operation chart/Maximize } \\
\text { the total power generation of cascade } \\
\text { reservoirs over the entire planning } \\
\text { horizon }\end{array}$ & None & $\begin{array}{l}\text { The combination of the total output operation } \\
\text { chart and the output distribution ratios performed } \\
\text { better in power generation and assurance rate; } \\
\text { the output distribution rules obtained via this } \\
\text { model enabled the operation at the current } \\
\text { stage to have an optimal influence on } \\
\text { subsequent stages, resulting in the maximum } \\
\text { total power generation of all operation stages. }\end{array}$ \\
\hline $\begin{array}{l}\text { Taghian et } \\
\text { al. (2014) }\end{array}$ & $\begin{array}{l}\text { Conventional rule curve coupled with } \\
\text { hedging rules/ Minimize the cost - the } \\
\text { unit penalties for violations } \\
\text { corresponding flow deviation from the } \\
\text { desired condition and storage violation } \\
\text { from the rule curve }\end{array}$ & None & $\begin{array}{l}\text { The proposed policies performed better in the } \\
\text { long-term system and the annual system } \\
\text { during failure years. However, as the hedging } \\
\text { rules will adjust demand when a drought is } \\
\text { expected, the number of years with small } \\
\text { shortages is increased. }\end{array}$ \\
\hline $\begin{array}{l}\text { Jiang et al. } \\
\text { (2016) }\end{array}$ & $\begin{array}{l}\text { Energy storage operation } \\
\text { chart/Maximize the guaranteed output } \\
\text { and annual average power generation }\end{array}$ & None & $\begin{array}{l}\text { Compared with the current operation method, } \\
\text { the optimized operation chart resulted in a } 6.8 \% \\
\text { increase in guaranteed output and a } 0.26 \% \\
\text { increase in annual average power generation. }\end{array}$ \\
\hline $\begin{array}{l}\text { Zhou and } \\
\text { Guo } \\
(2013)\end{array}$ & $\begin{array}{l}\text { Reservoir operating rule curves/Mini- } \\
\text { mize the downstream flood control risk; } \\
\text { Maximize the downstream water de- } \\
\text { mand, water diversion, power genera- } \\
\text { tion and ecological water demand. }\end{array}$ & $\begin{array}{l}\text { Optimize ecological supply } \\
\text { water curve }\end{array}$ & $\begin{array}{l}\text { Ecological operating rule curve can alleviate } \\
\text { the negative effect of dam on the river } \\
\text { ecosystem without reducing conservation } \\
\text { benefits and flood control standard. }\end{array}$ \\
\hline $\begin{array}{l}\text { Sale et al. } \\
(1982)\end{array}$ & $\begin{array}{l}\text { Reservoir operating strategies/ } \\
\text { Maximize \{i.e., 'maximize the } \\
\text { minimum') function of WUA values } \\
\text { produced by the expected releases for } \\
\text { each time period. }\end{array}$ & $\begin{array}{l}\text { The flow corresponding to the } \\
\text { optimal fish habitat area is used } \\
\text { as the optimal ecological } \\
\text { flow, and make the reservoir } \\
\text { discharge is as close as } \\
\text { possible to the optimal flow }\end{array}$ & $\begin{array}{l}\text { The linkage between IFN (biological instream } \\
\text { flow needs)/EQ(environmental quality) object- } \\
\text { tive and conventional reservoir design param- } \\
\text { eters is obtained, and the operation under the } \\
\text { optimized policies could improve instream } \\
\text { flows provided below lake shelbyville }\end{array}$ \\
\hline $\begin{array}{l}\text { Suen and } \\
\text { Eheart } \\
(2006)\end{array}$ & $\begin{array}{l}\text { Reservoir operating strategies } \\
\text { /Maximize ecosystem needs, public } \\
\text { (domestic and industrial water supply) } \\
\text { and agricultural water needs, and power } \\
\text { generation. }\end{array}$ & $\begin{array}{l}\text { Maintain the flow regimes as } \\
\text { similar as possible to that } \\
\text { least affected by human } \\
\text { activities (ecological flow } \\
\text { regimes) }\end{array}$ & $\begin{array}{l}\text { The optimized model can find the Pareto } \\
\text { optimal frontier between ecosystem and } \\
\text { human water needs; and provide optimal } \\
\text { trade-off between human needs and } \\
\text { maintenance of ecological flow regimes. }\end{array}$ \\
\hline $\begin{array}{l}\text { Yang et al. } \\
(2012)\end{array}$ & $\begin{array}{l}\text { Reservoir operating } \\
\text { strategies/Maximize the ecological } \\
\text { requirement of rivers under the flood } \\
\text { control requirement }\end{array}$ & $\begin{array}{l}\text { Take natural flow regimes } \\
\text { into ecological objective } \\
\text { based on the RVA method. }\end{array}$ & $\begin{array}{l}\text { The change of post-dam water regime is } \\
\text { controlled in the ecological requirement-based } \\
\text { model. This can improve the riverine } \\
\text { environment, but the power generation is } \\
\text { reduced because of excessive abandon water. }\end{array}$ \\
\hline $\begin{array}{l}\text { Rossel and } \\
\text { de la } \\
\text { Fuente } \\
(2015)\end{array}$ & $\begin{array}{l}\text { Reservoir operating strategies } \\
\text { /minimize the total operational cost of } \\
\text { the electric power plants }\end{array}$ & $\begin{array}{l}\text { Add ecological flow } \\
\text { constraint to the multi- } \\
\text { objective optimization model } \\
\text { to improve the water quality }\end{array}$ & $\begin{array}{l}\text { Under a wet scenario, the environmental flow } \\
\text { constraint has no signify-cant effects on any of } \\
\text { the parameters (hydropower generation, water } \\
\text { level variations) during the simulation period. } \\
\text { For normal and dry hydrology, the inclusion } \\
\text { of environmental constraint to the operation of } \\
\text { the hydropower plant increased chlorophyll-a } \\
\text { concentration in the reservoir. }\end{array}$ \\
\hline $\begin{array}{l}\text { Chen et al. } \\
(2015)\end{array}$ & $\begin{array}{l}\text { Daily reservoir operation strategies } \\
\text { /maximize the annual hydropower } \\
\text { generation }\end{array}$ & $\begin{array}{l}\text { Add ecological flow } \\
\text { constraint to the optimization } \\
\text { model: the discharge from } \\
\text { reservoir to de-watered river } \\
\text { channel should meet a time- } \\
\text { varying flow requirement }\end{array}$ & $\begin{array}{l}\text { The monthly-based optimization model } \\
\text { provides an approximate result for further } \\
\text { improvement, and then the } 10 \text {-day based and } \\
\text { daily-based models give a detailed operation } \\
\text { scheme by scaling down the time within the } \\
\text { bounds determined in the previous model. }\end{array}$ \\
\hline
\end{tabular}


studies was to improve the average ecological benefit of the basin without considering the possible negative impacts caused by wet/dry events (e.g., flood or drought) on the ecological systems (Zhou and Guo, 2013). On the other hand, ecological requirements are sometimes considered as constraints (Mei et al., 2009; Yin and Yang, 2011; Chen et al., 2013), making it easy to avoid serious ecological damage under extreme conditions but difficult to maximize the overall ecological benefit. Thus, challenge remains to balance the average ecological benefit over a long period of time and the ecological damage under wet/dry conditions.

Given the complexity in the optimization of reservoir operation chart, the ecological flow is simply assumed to be a constant, which can be estimated by the Tennant method or other simple methods (Tharme, 2003). The discharge demand of fish species in different growing seasons may vary substantially. The Physical Habitat Simulation Model (PHABSIM) is a classical habitat simulation technique proposed in the early 1970 s. Now, it has been widely used to characterize changes in the hydraulic habitat of fish species in response to the alteration of flow regimes, based on which the optimal ecological flow can be obtained (Wilding et al., 2014). For instance, PHABSIM has been used to determine the ecologically acceptable flow regimes of Kielder reservoir and water transfer system (Gibbins et al., 2001) and the ecological demand of fish species in China (Li et al., 2015; Wen et al., 2016)

In this study, we proposed a new hydropower-ecological operation chart of cascade hydropower stations, in which limited ecological curves were introduced and optimized to alleviate the negative impacts caused by drought or flood events on fish habitat and to maintain the long-term average fish habitat quality without reducing power generation. The limited ecological curves were optimized with the goal of reducing the ecological damage frequency in wet and dry extremes and then incorporated into conventional operation chart (COC) to form an optimized ecological operation chart (OEOC), and parameters such as reduction coefficient and ecological conservation degree target were proposed to flexibly balance short- and long-term ecological benefit and power generation benefit. Finally, a case study was performed with Jasajiang (JS) and Madushan (MDS) cascade reservoirs on the Yuan River in southwestern China to evaluate the performance of OEOC and the effects of different combinations of parameters.

\section{Data and Methods}

\subsection{Study Area and Data}

The Yuan River is located in southwestern China (East: $100.01^{\circ} \sim 105.67^{\circ}$, North: $22.45^{\circ} \sim 25.53^{\circ}$ ), as shown in Figure 1. The Lishe River and the Shiyang River, the two main upstream tributaries of the Yuan River, originate from the Weishan City of Yunnan Province and join at the Sanjiangkou, and then it flows through the southwestern China and Vietnam with a total length of $692 \mathrm{~km}$ and a drainage area of $34,629 \mathrm{~km}^{2}$. Its large branches include the Nanxi River, Tengtiao River and Panlong River. Although the Yuan River is famous for its high aquatic productivity and hydropower potential, most of its branches and the upper reaches of the river are essentially unexploited. JS and MDS hydropower stations are the two largest hydropower stations constructed on the Yuan River, whose main functions are power generation, ecological protection and flood control. The basic parameters of the JS-MDS cascade hydro-power stations are shown in Table 2.

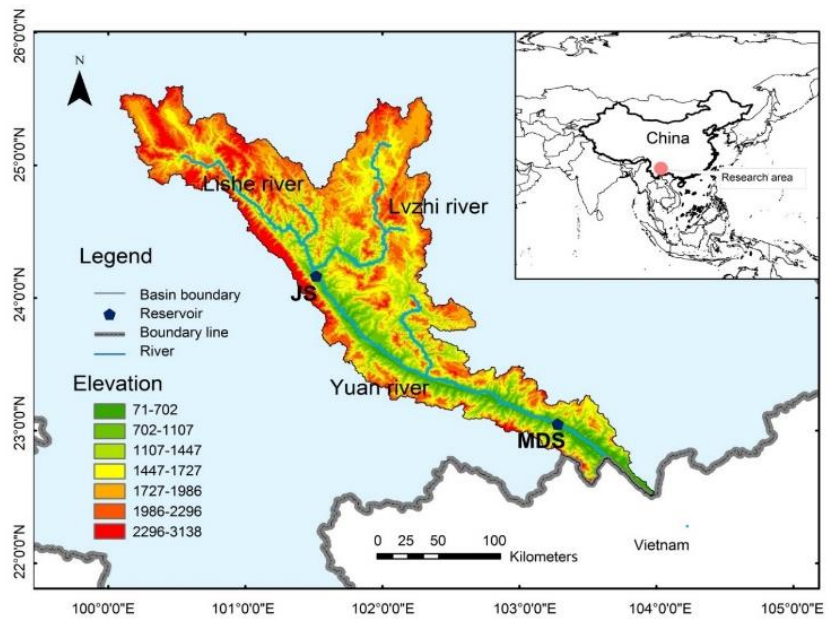

Figure 1. The geographic location and river networks of JS and MDS reservoirs.

Table 2. Basic Properties of the JS-MDS Cascade Hydropower Stations

\begin{tabular}{llll}
\hline Properties & Unit & JS & MDS \\
\hline Basin area & $\mathrm{km}^{2}$ & 18102 & 31356 \\
Regulation ability & - & Annual & Seasonal \\
Normal water level & $\mathrm{m}$ & 675 & 217 \\
Dead water level & $\mathrm{m}$ & 640 & 199 \\
Output efficiency & - & 8.6 & 8.8 \\
$\begin{array}{l}\text { Guaranteed output } \\
\text { Available storage }\end{array}$ & $\mathrm{MW}$ & 80.48 & 78.6 \\
$\begin{array}{l}\text { Turbine installed } \\
\text { capacity }\end{array}$ & $\mathrm{MW}$ & $90 \times 3$ & 260 \\
$\begin{array}{l}\text { Head loss } \\
\text { Maximum turbine }\end{array}$ & $\mathrm{m}$ & 820 & $96 \times 3$ \\
release & $\mathrm{m} 3 / \mathrm{s}$ & $90 \times 3$ & 0.89 \\
* Q is the turbine release & & & $163 \times 3$ \\
\hline
\end{tabular}

The study area has a subtropical plateau monsoon climate with distinct wet and dry seasons but a small temperature difference between different seasons, and the main aquatic organisms include phytoplankton, zooplankton, zoobenthos and fish. Cyprinus rubrofuscus Lacépède is the major fish species in the ecological preservation area located downstream of the JS reservoir on the Yuan River, and it is an economically and ecologically important fish species and plays a critical role in the biodiversity of the river. B. rutilus is another economically and ecologically important fish species distributed downstream of the MDS reservoir, and its population is significantly reduced after the operation of the reservoir due to its short-term migra- 
tion habit for breeding. In this study, Cyprinus rubrofuscus Lacépède and B. rutilus were selected as the representative fish species of the downstream reaches of JS reservoir and MDS reservoir, respectively.

The flow rates of JS and MDS reservoirs were collected at the Yuan River station and Manhao station (Figure 1) on a monthly basis from January 1981 to December 2010, respecttively.

\subsection{Physical Habitat Simulation Model}

PHABSIM can be used to characterize the relationship between stream flow and physical habitat of a given fish species, based on which the optimal ecological flow required for the fish species at different growing stages can be obtained (Bovee and Milhous, 1978). PHABSIM is composed of hydraulic simulation and habitat modeling modules (Waddle, 2001). In the former module, the MANSQ model (Manning's equation) is used to determine the depth and velocity of the stream; while in the latter module, the Habitat Suitability Index (HSI), which can reflect the preferences of the fish species for flow velocity, depth, and channel properties (Bovee, 1986; Booker and Acreman, 2007), is used to obtain the physical habitat availability (WUA) for each fish species/life stage, as shown in Equations 1 and 2:

$$
\begin{aligned}
& \text { WUA }=\sum_{i=1}^{n} A_{i} \times C_{i} \\
& C_{i}=f\left(v_{i}\right) \times f\left(d_{i}\right) \times f\left(c_{i}\right)
\end{aligned}
$$

where $A_{i}$ is the area of cross section $i, C_{i}$ is the combined HSI of cross section $i$, and $v_{i}, d_{i}$, and $c_{i}$ are the HSI of cross section $i$ with respect to the velocity, flow depth and substrate size, respectively.

The optimal ecological discharge corresponds to the vertex in the WUA-discharge curve. However, it is practically impossible to exactly follow the optimal ecological flow in reservoir operation. Li et al. (2015) used landscape indices and WUA to determine the ecological discharge requirement of a given fish species. Here, the ecological requirements can be described by the discharge range corresponding to the area exceeding a given WUA in the WUA-discharge curve, which can be more flexible to balance hydropower generation and ecological conservation. Furthermore, ecological target is a flexible technique to better adapt to the complex situation in practical operation of reservoirs. Considering the competitiveness of diverse objectives, a higher ecological target implies a higher ecological conservation degree and thus more sacrifice of other objectives. The target should be adjusted dynamically during the operation process according to current and expected conditions. A schematic of this procedure with a $80 \%$ WUA is shown in Figure 2.

If the runoff is within the optimal ecological flow range ([Q1, Q2] in Figure 2) or the conservation degree is larger than the conservation degree objective ( $80 \%$ as an example here), then the ecological condition is conserved; otherwise, the eco- logical condition is damaged. Accordingly, the ecological damage frequency refers to the ratio of ecologically damaged months to the total number of months in the study period. For instance, there are a total of 120 months from January 2000 to December 2010 and ecological damage is assumed to occur in 12 months, then the ecological damage frequency is $12 / 120=$ $10 \%$.

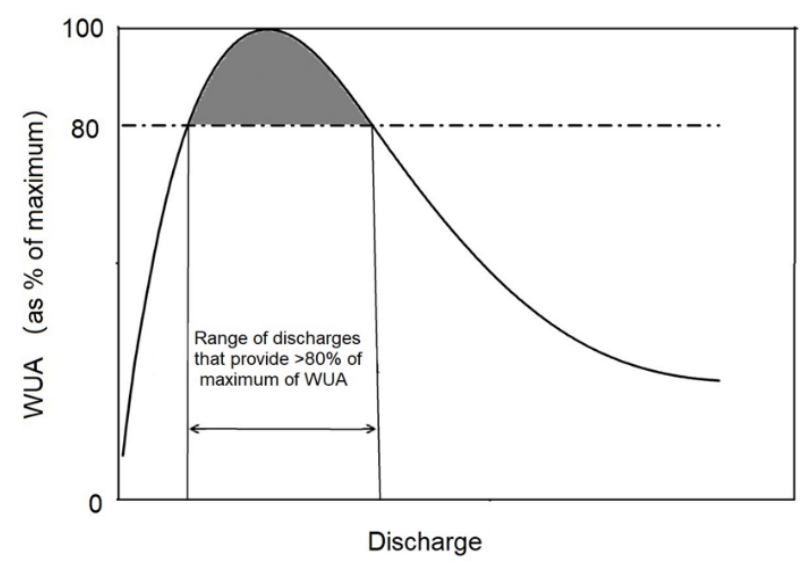

Figure 2. A schematic for the determination of ecological requirements.

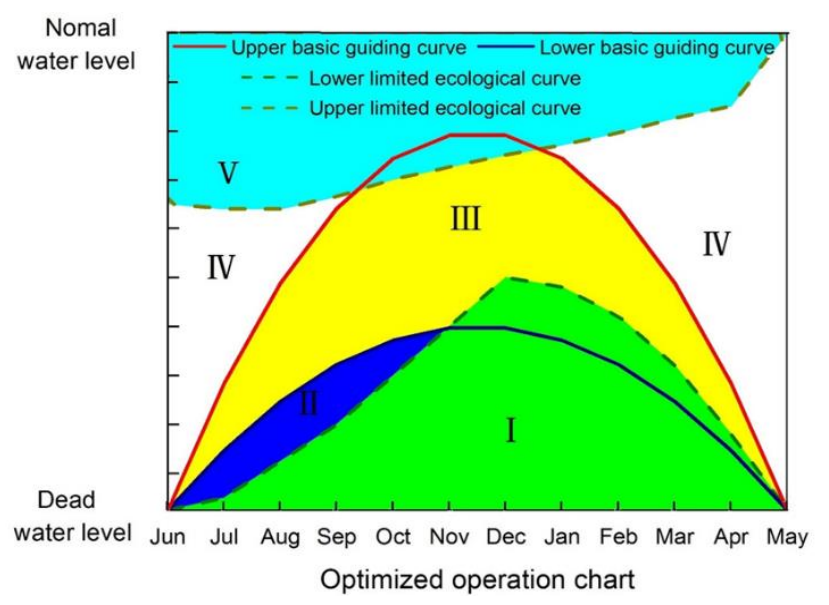

Note: I. Lower limited ecological zone; II. Reduced output zone; III. Guaranteed output zone; IV. Increased output zone; V. Upper limited ecological zone.

Figure 3. A schematic of the reservoir operation chart with upper and lower limited ecological curves.

\subsection{Optimization of the Operation Chart of Cascade Reservoirs}

\subsubsection{Framework}

The reservoir operation chart has found numerous applications in reservoir operation due to its ease of implementation. In the operation chart, the total storage space of a reservoir is divided into a number of zones, and the release target of the reservoir at the beginning of each month can be defined based on the respective zone in which the water level is located 
(Taghian et al., 2014). The COC is often composed of the upper basic guiding curve, lower basic guiding curve and increased output curve, which can divide the chart into the guaranteed output zone, reduced output zone, and increased output zone. As shown in Figure 3, when the reservoir water level falls in the reduced output zone (Zone II) the output should be reduced; when it falls in the increased output zone (Zone IV), the output should be increased; in the guaranteed output zone (Zone III), the planet should be running to maintain the firm capacity. The main objective of the operation chart of a hydro-power station is to maximize the power output, which often does not take into account the potential ecological consequences.

In order to address this issue, this study proposed a new method to optimize COC with the purpose of minimizing the ecological impacts in hydrological extremes on the premise of ensuring the power generation and ecological conservation. This is achieved by incorporating the upper and lower limited ecological curves into COC. The upper limited ecological curve is derived using the upper boundary of the ecological discharge range determined from WUA-discharge curve, and the area above the upper limited ecological curve is the upper limited ecological zone (zone V); similarly, the area below the lower limited ecological curve is the lower limited ecological zone (zone I ), as shown in Figure 3. When the water level is located in the upper/lower limited ecological zone, then the release should equal to the upper or lower boundary of the ecological discharge range, respectively. However, it is important to note that the limited ecological zone has the priority over other zones. When the limited ecological zone overlaps with other zones in the operation chart, the discharge should follow the rules specified in the limited ecological zone.

\subsubsection{Development and Optimization of Limited Ecological Curves}

\subsubsection{Development of Limited Ecological Curves}

The operation chart is a practical and widely used reservoir scheduling rule consisting of several guiding curves, which can divide the reservoir capacity into several zones. In order to reduce the ecological damage frequency in flood or drought periods, new guiding curves are incorporated into the conventional operation chart, forming the hydropower-ecological operation chart, and these new guiding curves are referred to as limited ecological curves.

An important consideration in the study of hydrological extremes is the temporal scale (hourly, daily, weekly, and monthly) as the characteristics of hydrological extremes may differ substantially on different temporal scales. Unlike realtime reservoir operation, the operation chart is a rule-based policy, which is often derived based on the historical hydrological data on a long-time (usually weekly, ten-day, or monthly) scale, therefore temporal scale the hydrological extremes should be the same. In this study, the monthly scale is considered in operation chart optimization, and thus the hydrological extreme refers to the situation in which the monthly runoff is significantly lower or higher than the historical monthly runoff.
The limited ecological curve can be obtained by the reverse calculation based on the principle of water balance. Specifically, the water level at the beginning of reservoir impoundment is reversely calculated from the dead water level at the end of a given period according to the inflow amount and the lower/upper boundary of the ecological flow range in this period using the water balance formula, and the upper/lower envelope curve in dry years is defined as the lower/upper limited ecological curve, respectively. In this study, the limited ecological curves at an ecological conservation target of 60, 70, 80, and $90 \%$ are obtained, which together with the COC form the ecological operation chart (EOC).

However, it is important to note that the limited ecological curves are not hard constraints, which can cause the problem of no solution under extremely dry or wet conditions. It is a very flexible regulation technique, which can reduce the frequency of ecological damage under extremely dry or wet conditions, and it can also make adaptive adjustments in case of conflict with other important objectives.

\subsubsection{Optimization of Limited Ecological Curves}

The above limited ecological curves need to be optimized as manual intervention is required, which may affect the performance of the novel operation chart. In this study, an optimization model for limited ecological curves is proposed, including the objective function, constraints and optimization algorithm. Finally, the optimized ecological operation chart (OEOC) is obtained and compared with the conventional one. The objecttives and constraints of OEOC are described as follows:

\section{(1) Objective functions of OEOC}

The aim of limited ecological curves is to alleviate ecological degradation in hydrological extremes, and to balance the overall hydropower and ecological benefits. Thus, the objective function is to minimize the ecological damage frequency, which refers to the ratio of the periods with ecological damage to the total number of periods, as expressed in Equation 3 . The hydropower production and average ecological conservation degree are taken as constraints:

$$
E_{1}=\min \frac{\sum_{i=1}^{n} \sum_{t=1}^{T} m_{i, t}}{T} \times 100 \% ; m_{i, t}= \begin{cases}0, & R_{i, t} \geq R_{d, t} \\ 1, & R_{i, t} \leq R_{d, t}\end{cases}
$$

where $E_{1}$ is the ecological damage frequency, $n$ is the number of cascade reservoirs, $T$ is the total time step, $R_{d, t}$ is the ecological target, and $R_{i, t}$ is the ecological conservation degree corresponding to the discharge of hydropower station $i$ during period $t$, respectively.

\section{(2) Constraints}

(1) Water balance constraints

$V_{i, t+1}=V_{i, t}+\left(I_{i, t}-Q_{i, t}\right) g \Delta t, i=1,2, \ldots, n ; t=1,2, \ldots, T$

where $V_{i, t}$ is the storage of reservoir $i$ during period $t\left(\mathrm{~m}^{3}\right), I_{i, t}$ and $Q_{i, t}$ are the inflow and outflow of reservoir $i$ during period 
$t\left(\mathrm{~m}^{3} / \mathrm{s}\right)$, respectively.

(2) Reservoir storage constraints

$V_{i, t}^{\min } \leq V_{i, t} \leq V_{i, t}^{\max }, i=1,2, \ldots, n ; t=1,2, \ldots, T$

where $V_{i, t}^{\min }$ and $V_{i, t}^{\max }$ are the minimum and maximum storage limit of reservoir $i$ during period $t\left(\mathrm{~m}^{3}\right)$, respectively.

(3) Output constraints

$N_{i, \min } \leq N_{i, t} \leq N_{i, \max }, i=1,2, \ldots, n ; t=1,2, \ldots, T$

where $N_{i, t}$ is the output of hydropower station $i$ during period $t$ (W), and $N_{i, \min }$ and $N_{i, \max }$ are the minimum and maximum output of hydropower station $i(\mathrm{~W})$, respectively.

(4) Outflow constraints

$Q_{i, t}^{\min } \leq Q_{i, t} \leq Q_{i, t}^{\max }, i=1,2, \ldots, n ; t=1,2, \ldots, T$

where $Q_{i, t}^{\min }$ and $Q_{i, t}^{\max }$ are the minimum and maximum out-flow of reservoir $i$ during period $t\left(\mathrm{~m}^{3} / \mathrm{s}\right)$, respectively.

(5) Minimum power generation and ecological benefit constraints

To ensure the hydropower production and ecological conversation after the incorporation of limited ecological curves, the relative decrease rate of hydropower generation and ecological conversation degree should be less than 5\% compared with the performance without limited ecological curves:

$$
E_{2} \geq \beta E_{e} E_{3} \geq \gamma E_{p}
$$

where $E_{e}$ and $E_{p}$ are the power generation and ecological conservation degree of the operation chart without limited ecological curves, and $\beta$ and $\gamma$ are the reduction coefficients, both of which are set to 0.95 in this study.

\subsubsection{Optimization Algorithms}

The optimization of the reservoir operation chart is a multi-dimensional and multi-stage problem. There are many optimization algorithms such as Dynamic Programing and some Evolutionary Algorithms (EA) such as Genetic Algorithm (GA) and Differential Evolution Algorithm (DE). Although most EAs have been successfully used in optimization of reservoir operation charts, DP is not an appropriate approach for such a multi-dimensional and multi-stage problem because of curse of dimensionality. The reservoir storage is divided into several zones in the operation chart by guiding curves. It is possible that the optimization technique could propose the same releasing policy in different zones, which would affect the crossover and variation process of the EAs, resulting in unstable optimization performance.

Dynamic Programming Successive Approximation (DPSA) has been shown to be particularly effective in solving multi-dimensional problems (Larson and Korsak, 1970; Shi et al., 2015). Its basic idea is to decompose the problem with multiple decision variables into a number of subproblems, and each sub-problem has only one decision variable and less state variables than the original problem, resulting in a reduction of computational cost and time and consequently a rapid progresssion to an excellent solution (Yi et al., 2003; Opan, 2010). In this study, COC is taken as the initial solution. The distance between the guiding curve $f$ and the guiding curve $g$ is used to describe the similarity between the two curves, which is defined as in Equation 9:

$D(f, g)=\sum_{k=1}^{K}\left|f_{k}-g_{k}\right|$

where $f_{k}$ and $g_{k}$ are the reservoir water level for the guiding curve $f$ and $g$ during period $k$, respectively.

Similarly, the distance between two operation charts with the same type of guiding curves is defined as in Equation 10:

$$
D(C 1, C 2)=\sum_{s=1}^{S} \sum_{k=1}^{K}\left|C 1_{s, k}-C 2_{s, k}\right|
$$

where $C 1_{s, k}$ and $C 2_{s, k}$ are the reservoir water level for the guiding curve $s$ in the operation chart $C 1$ and $C 2$ during period $k$, respectively.

The optimization processes can be summarized in the following steps (Figure 4):

Step 1: Fix the values of all points on the operation chart except the one to be optimized. This point is optimized within the permitted scope, and simulation calculation is carried out using the long series runoff data. Then, the point is replaced with the one that can maximize the objectives of all operation stages.

Step 2: Optimize the point for the next stage on the current guiding curve $L$ until all points on this curve are optimized.

Step 3: Repeat Steps $1 \sim 2$ until the distance between two guiding curves meet the accuracy requirement.

Step 4: Repeat Steps $1 \sim 3$ for other guiding curves which need to be optimized on the operation chart from the bottom to the top, and finally a new operation chart is obtained.

Step 5: Calculate the distance between the two operation charts. If the distance meets the accuracy requirements, then stop counting; otherwise the obtained operation chart is taken as a new operation chart, and repeat Steps $1 \sim 4$.

\section{Results}

\subsection{Determination of the Optimal Ecological Discharge}

Given their high genetic diversity and economic value, Cyprinus rubrofuscus Lacépède and Bagarius rutilus $\mathrm{Ng}$ et Kottelat (B. rutilus) are selected as the target fish species of the Yuan River in this study. A nature reserve is established in the downstream of JS Reservoir to protect Cyprinus rubrofuscus Lacépède. However, the habitat and population of B. rutilus decrease significantly in recent years, and now it mostly lives in the downstream of MDS Reservoir. The relationship between 


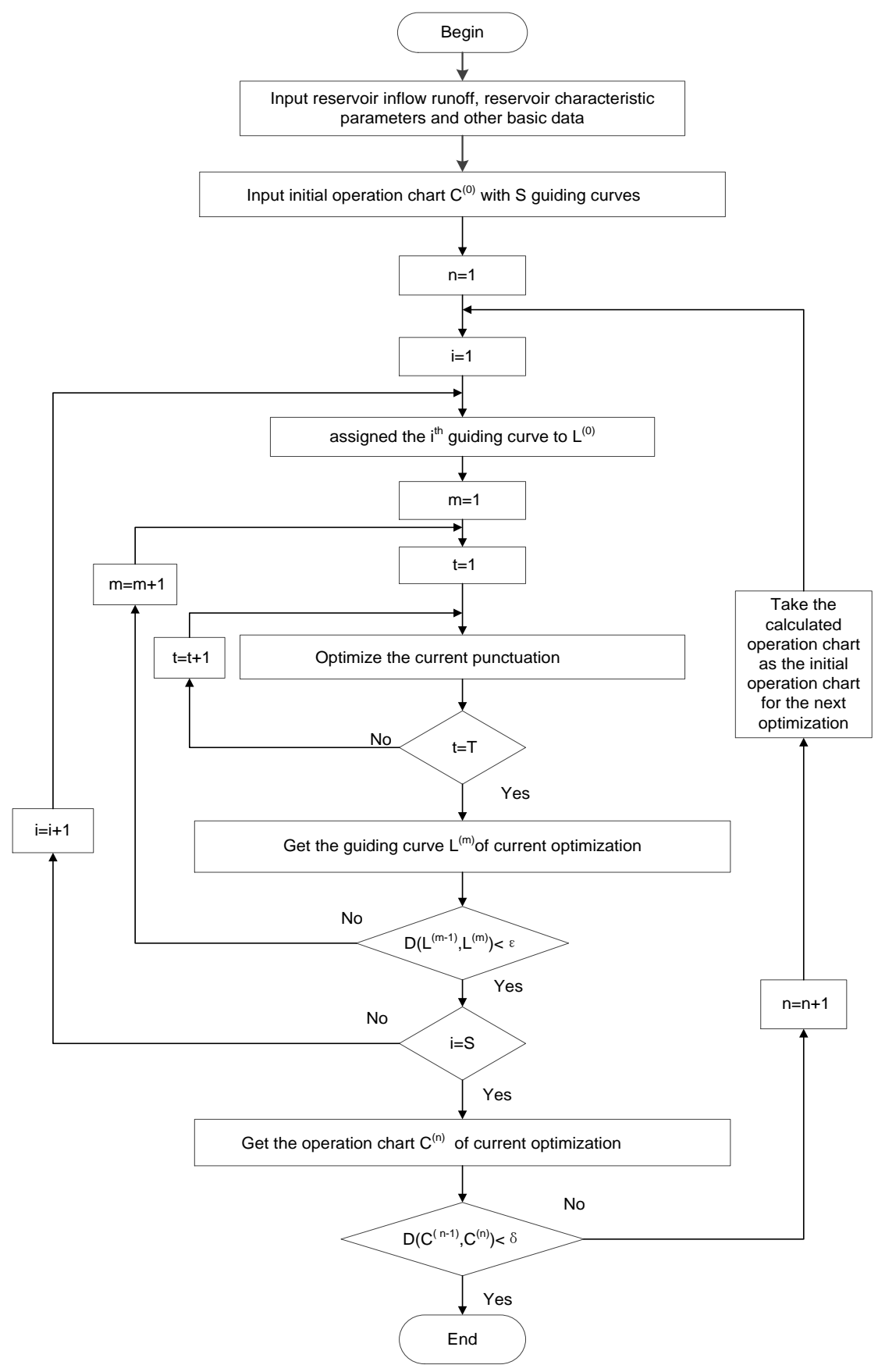

Figure 4. The flowchart of DPSA in guiding curve optimization.

Table 3. The Optimal Ecological Discharge Range of Cyprinus Rubrofuscus Lacépède and B. Rutilus

\begin{tabular}{llllll}
\hline \multirow{2}{*}{ Fish species } & \multirow{2}{*}{ Month } & \multicolumn{4}{l}{ Optimal ecological discharge $\left(\mathrm{m}^{3} / \mathrm{s}\right)$} \\
\cline { 2 - 6 } & & $90 \%$ & $80 \%$ & $70 \%$ & $60 \%$ \\
\hline Cyprinus rubrofuscus & Dec $\sim$ Mar & $57.2 \sim 162.5$ & $41.8 \sim 199.9$ & $32.6 \sim 241.4$ & $25.7 \sim 2.9$ \\
Lacépède & Apr $\sim$ Aug & $48.0 \sim 202.4$ & $34.6 \sim 246.8$ & $24.5 \sim 291.6$ & $17.9 \sim 373.0$ \\
& Sep $\sim$ Nov & $194.3 \sim 582.3$ & $114.8 \sim 679.5$ & $73.2 \sim 785.4$ & $52.4 \sim 895.4$ \\
B. rutilus & Apr $\sim$ Jul & $282.8 \sim 624.1$ & $204.1 \sim 744.4$ & $158.4 \sim 849.5$ & $121.7 \sim 966.7$ \\
& Aug $\sim$ Oct & $317.6 \sim 697.3$ & $237.9 \sim 836.1$ & $158.4 \sim 849.5$ & $144.4 \sim 1089.6$ \\
& Nov $\sim$ Mar & $224.6 \sim 563.0$ & $150.6 \sim 694.5$ & $104.7 \sim 822.4$ & $54.2 \sim 954.0$ \\
\hline
\end{tabular}


WUA and flow rate for different life stages of Cyprinus rubrofuscus Lacépède and B. rutilus in the Yuan River is obtained using the PHABSIM model, as shown in Table 3 (Wen et al., 2016).

\subsection{Optimization of Multipurpose Reservoir Operation Chart}

In this study, EOCs at an ecological target of $60 \%, 70 \%$, $80 \%$, and $90 \%$ are obtained by incorporating the limited ecological curves into COC. In doing so, the limited ecological curves are calculated according to the historical runoff series for the period $1981 \sim 2010$ and then optimized. JS and MDS reservoirs are operated following COC, EOC, and OEOC. The limited ecological curves and optimized limited ecological curves of JS and MDS reservoirs at an ecological target of 60, 70, 80, and 90\% are shown in Figure 5, respectively.

In general, increasing the ecological target from $60 \%$ to $90 \%$ results in an upward movement of the lower limited ecological curve but a downward movement of the upper limited ecological curve in EOC of JS and MDS reservoirs, and consequently an increase in the area of the limited ecological zone. This is because as the ecological target increases, a more stringent requirement is imposed on the ecological discharge range. The increase of the lower limited ecological curve allows the ecological conservation degree not to exceed the lower boundary. On the other hand, the upper limited ecological curve is reduced, and the decrease of the maximum ecological discharge allows the discharge in the main flood period not to exceed the upper boundary, and thus it is necessary to discharge water at the beginning of the wet season. At an ecological target of $60 \%$ and $70 \%$, the lower limited ecological curve of OEOC is higher than that of EOC for both JS and MDS reservoirs. Accordingly, the lower limited ecological zone of OEOC is larger than that of EOC. This is because in dry season, the average discharge for power generation in the reduced output zone and guaranteed output zone of JS Reservoir is 38.4 and 76.7 $\mathrm{m}^{3} / \mathrm{s}$, respectively, which is higher than the minimum discharge at an ecological target of $60 \%$ and $70 \%$ (e.g., 25.7 and $32.6 \mathrm{~m}^{3} / \mathrm{s}$ from December to March of the next year, respectively); whereas that of MDS Reservoir is 112.4 and $146.4 \mathrm{~m}^{3} / \mathrm{s}$, respectively, which is also higher than the minimum discharge at an ecological target of $60 \%$ and $70 \%$ (e.g., 54.2 and $104.7 \mathrm{~m}^{3} / \mathrm{s}$ form November to March of the next year, respectively). As the limited ecological curve increases, the minimum ecological discharge is used in case of low reservoir storage in order to save more water for later periods.

At an ecological target of $90 \%$, the lower limited ecological zone of OEOC is smaller than that of EOC, which can be attributed to the higher minimum ecological discharge required to maintain this ecological target. At the beginning of the wet season, the lower limited ecological zone overlaps part of the increased output zone, resulting in an increase in discharge. For instance, the average discharge of JS Reservoir in the 1.5 -time increased output zone is $115.1 \mathrm{~m}^{3} / \mathrm{s}$, which is lower than the minimum discharge of $194.8 \mathrm{~m}^{3} / \mathrm{s}$ required at an ecological target of $90 \%$. Therefore, although the ecological requirement in early stages can be satisfied, ecological damage may occur more intensely in dry season, and also the decrease in water head in dry season can result in a decrease in power generation.

\subsection{Optimization Performance of JS-MDS Cascade Reservoirs}

\subsubsection{Simulation of Different Operation Charts at a $80 \%$} Ecological Target

The operation of JS and MDS reservoirs for the period 1981 2010 was simulated according to COC, EOC, and OEOC at a $80 \%$ ecological target as an example. The month OEOC at a $80 \%$ ecological target as an example. The month with a discharge higher than the maximum ecological discharge or lower than the minimum ecological discharge at a $80 \%$ ecological target is defined as an ecologically damaged month, as shown in Figure 6.

It clearly shows that at an ecological target of $80 \%$, the ecological damage frequency of JS and MDS reservoirs follows the order of COC > EOC > OEOC, and the ecological damage mainly results from the fact that the actual discharge is lower than the minimum ecological discharge. The main flood period of JS Reservoir is from July to September. More water can be stored at the beginning of the flood period, and the available storage capacity will be significantly reduced at the end of the flood period. In this circumstance, a large discharge can be expected. Although the allowable maximum ecological discharge of Cyprinus rubrofuscus Lacépède in the downstream of JS Reservoir is not always high throughout the year, it is significantly increased from September to November, resulting in a low frequency of ecological damage in JS Reservoir; while for MDS Reservoir, the allowable maximum ecological discharge of $B$. rutilus is always high throughout the year, also resulting in a low frequency of ecological damage. The ecological damage frequency of JS Reservoir due to low discharge is reduced from $9.17 \%$ under $\mathrm{COC}$ to $0 \%$ under OEOC, while that due to high discharge is reduced from $4.27 \%$ under $\mathrm{COC}$ to $3.61 \%$ under OEOC. Similarly, the ecological damage frequency of MDS Reservoir due to low discharge is reduced from $28.06 \%$ to $17.22 \%$, while that due to high discharge is reduced from $3.06 \%$ to $1.67 \%$.

The minimum ecological conservation degree of JS and MDS reservoirs under COC is $51.1 \%$ and $42.9 \%$, respectively. In comparison with $\mathrm{COC}$, EOC results in a decrease in ecological damage frequency, but an increase in ecological damage severity with a minimum ecological conservation degree of $30 \%$ and $17.6 \%$ for JS and MDS reservoirs, respectively; while OEOC results in a decrease in both ecological damage frequency and severity in ecologically damaged months, with a minimum ecological conservation degree of $60.8 \%$ and $44.6 \%$ for JS and MDS reservoirs, respectively.

\subsubsection{Optimization Performance of Different Operation} Charts at Different Ecological Targets

In order to explore the effects of ecological target on the ecological and power generation benefit, the performance of 
(a) EOC and OEOC of JS at $60 \%$ ecological targets

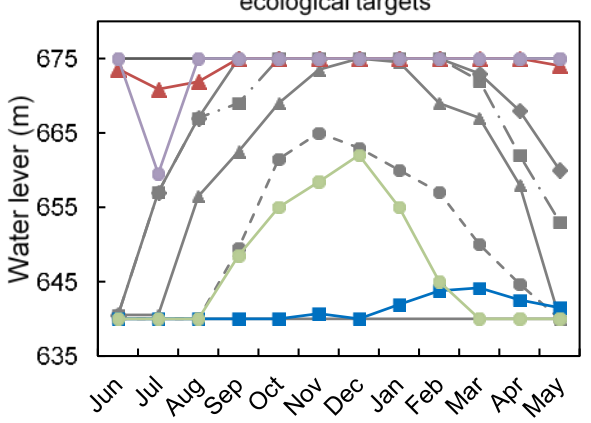

(c) EOC and OEOC of JS at $70 \%$ ecological targets

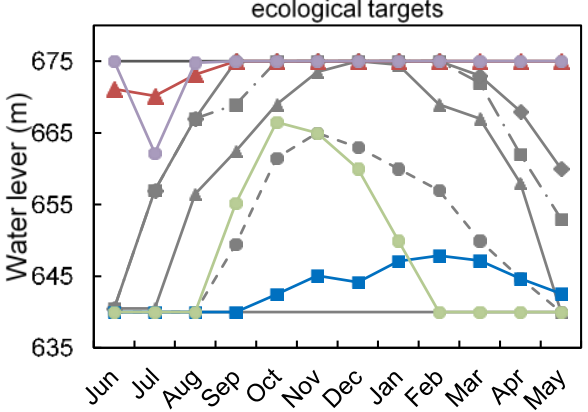

(e) EOC and OEOC of JS at $80 \%$ ecological targets

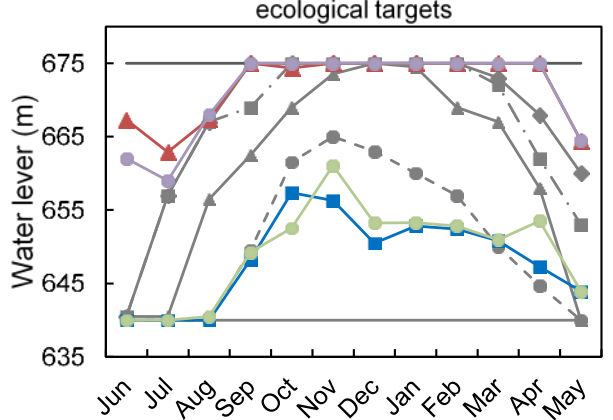

(g) EOC and OEOC of JS at $90 \%$ ecological targets

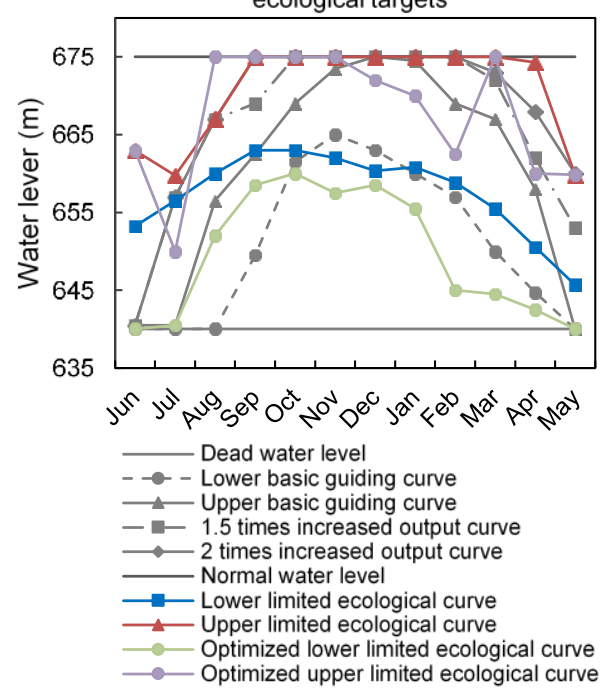

(b) EOC and OEOC of MDS at $60 \%$ ecological targets

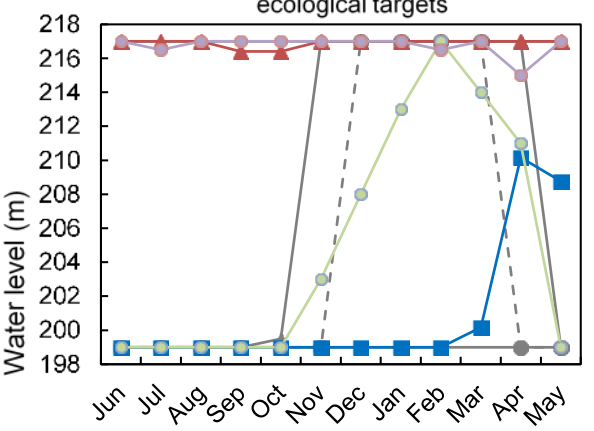

(d) EOC and OEOC of MDS at $70 \%$ ecological targets

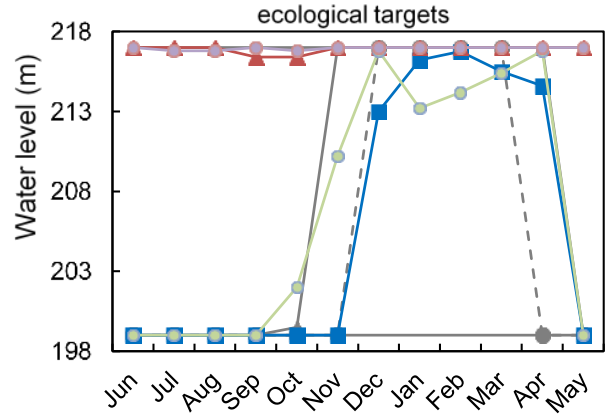

(f) EOC and OEOC of MDS at $80 \%$

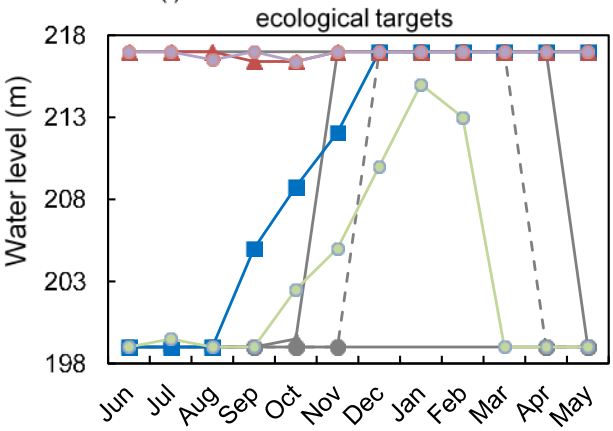

(h) EOC and OEOC of MDS at $90 \%$

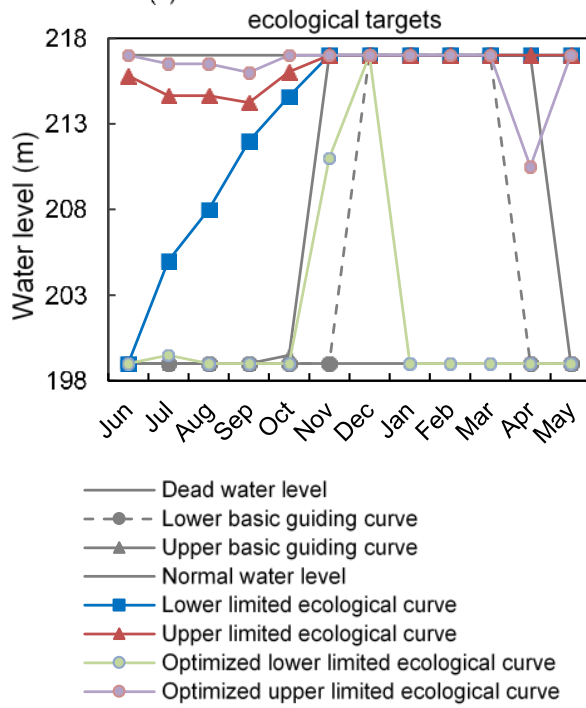

Figure 5. EOCs and OEOCs of JS and MDS reservoirs at different ecological targets. 


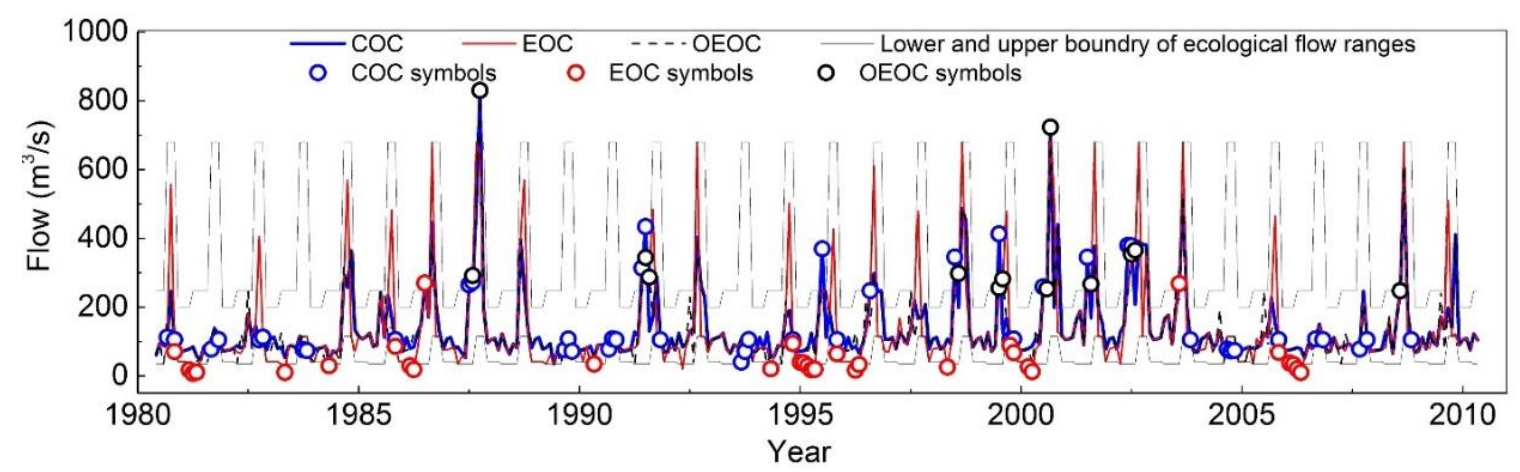

Figure 6. Time-series of monthly discharge of JS Reservoir for the period $1981 \sim 2010$ and the optimal ecological discharge range (circle refers to occurrence of ecological damage).

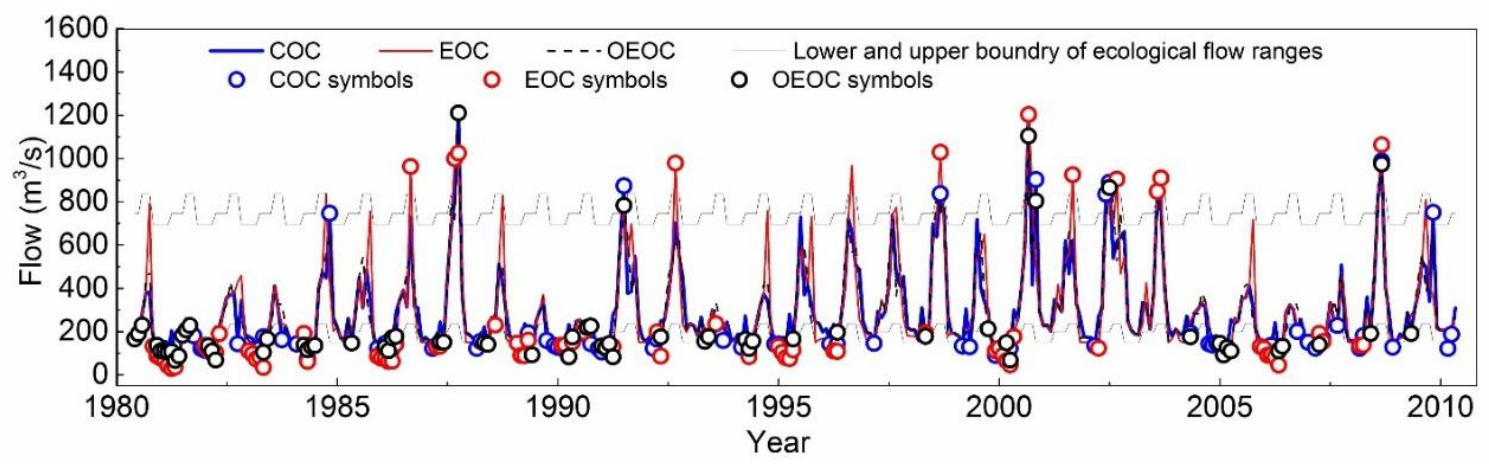

Figure 7. Time-series of monthly discharge of MDS Reservoir for the period $1981 \sim 2010$ and the optimal ecological discharge range (circle refers to occurrence of ecological damage).

Table 4. The Performance of JS Reservoir Based on Different Operation Chars at Different Ecological Targets

\begin{tabular}{|c|c|c|c|c|c|}
\hline \multirow{2}{*}{ Operation chart } & \multirow{2}{*}{ Performance } & \multicolumn{4}{|c|}{ Ecological target } \\
\hline & & $60 \%$ & $70 \%$ & $80 \%$ & $90 \%$ \\
\hline \multirow[t]{3}{*}{$\mathrm{COC}$} & Average output (MW) & 126.14 & 126.14 & 126.14 & 126.14 \\
\hline & Average ecological conservation degree $(\%)$ & 92.71 & 92.71 & 92.71 & 92.71 \\
\hline & Ecological damage frequency $(\%)$ & 1.39 & 4.17 & 13.89 & 21.94 \\
\hline \multirow[t]{3}{*}{ EOC } & Average output (MW) & 126.44 & 127.64 & 129.36 & 130.89 \\
\hline & Average ecological conservation degree $(\%)$ & 92.75 & 92.61 & 88.02 & 84.86 \\
\hline & Ecological damage frequency $(\%)$ & 0.00 & 1.11 & 12.50 & 32.78 \\
\hline \multirow[t]{3}{*}{ OEOC } & Average output (MW) & 127.20 & 128.44 & 128.20 & 127.96 \\
\hline & Average ecological conservation degree $(\%)$ & 92.11 & 91.87 & 91.77 & 90.16 \\
\hline & Ecological damage frequency $(\%)$ & 0.00 & 1.11 & 3.61 & 14.17 \\
\hline
\end{tabular}

Table 5. The performance of MDS Reservoir Based on Different Operation Charts at Different Ecological Targets

\begin{tabular}{llllll}
\hline \multirow{2}{*}{ Operation chart } & Performance & \multicolumn{2}{l}{ Ecological target } \\
\cline { 3 - 5 } & & $60 \%$ & $70 \%$ & $80 \%$ & $90 \%$ \\
\hline COC & Average output (MW) & 138.72 & 138.72 & 138.72 & 138.72 \\
& Average ecological conservation degree (\%) & 83.29 & 83.29 & 83.29 & 83.29 \\
\multirow{2}{*}{ EOC } & Ecological damage frequency (\%) & 3.06 & 11.39 & 31.11 & 64.72 \\
& Average output (MW) & 143.28 & 141.39 & 132.13 & 127.01 \\
& Average ecological conservation degree (\%) & 83.45 & 83.46 & 81.03 & 79.25 \\
OEOC & Ecological damage frequency (\%) & 2.22 & 3.89 & 29.44 & 63.33 \\
& Average output (MW) & 141.70 & 147.35 & 141.67 & 145.07 \\
& Average ecological conservation degree (\%) & 83.25 & 83.44 & 83.95 & 82.28 \\
& Ecological damage frequency (\%) & 1.39 & 3.33 & 18.89 & 49.17 \\
\hline
\end{tabular}


different operation charts at an ecological target of $60 \% \sim 90 \%$ was simulated, and the results are shown in Tables 4 and 5.

The annual average output of JS hydropower station under COC is $126.14 \mathrm{MW}$, and the average ecological conservation degree is $92.71 \%$. In comparison with COC, EOC results in an increase in power generation; a slight increase in average ecological conservation degree at an ecological target of $60 \%$; but a decrease in average ecological conservation degree at an ecological target of $70 \% \sim 90 \%$. In addition, the ecological damage frequency is reduced at all ecological targets except that at a $90 \%$ ecological target, and the most pronounced decrease is observed at a $70 \%$ ecological target. OEOC results in an improvement of power generation, a slight decrease in ecological conservation degree, and a significant improvement of ecological damage. The annual average output of MDS hydropower station under COC is $138.72 \mathrm{MW}$, and the average ecological conservation degree is $83.29 \%$. As the ecological target increases, the power generation and ecological conservation degree under EOC and OEOC first increase and then decrease, and the ecological damage frequency is reduced compared with that under COC. The power production, ecological conservation degree and ecological damage frequency of JS and MDS reservoirs under EOC and OEOC at different ecological targets

(a) Whole time period

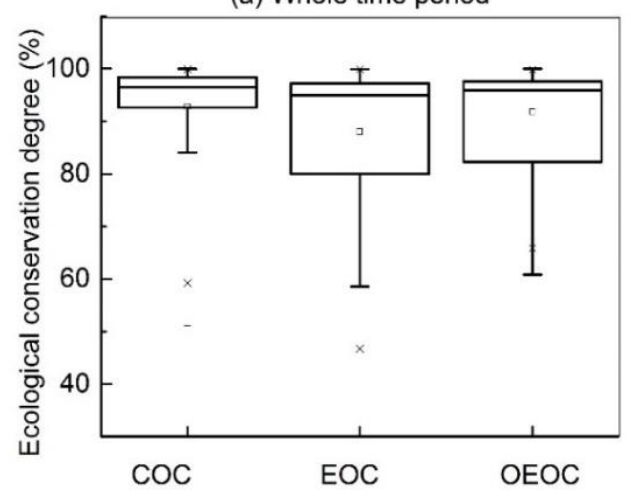

are shown in Figures 11 and 12, respectively.

\section{(1) Power generation}

Under EOC, the power production of JS-MDS cascade reservoirs decreases with the increase of ecological target from $60 \%$ to $90 \%$. However, it is noteworthy that increasing the ecological target results in an increase in power production of JS Reservoir, but a decrease in power production of MDS Reservoir. This is because the JS Reservoir is an annual-regulated reservoir with a storage capacity coefficient of $19.3 \%$, whereas the MDS Reservoir is a seasonal-regulated reservoir with a storage capacity coefficient of only $2.9 \%$. Thus, increasing the ecological target can have more significant impacts on the power generation of MDS Reservoir. Under OEOC, the power production of JS-MDS cascade reservoirs is higher than that under EOC. However, the power production of JS Reservoir at an ecological target of $80 \%$ and $90 \%$ is lower than that under EOC. This is because the JS Reservoir is located at the upstream of the MDS Reservoir and has a higher regulation capacity, the power generation of MDS Reservoir is improved at the expense of a reduction in power generation of JS Reservoir, in order to maximize the power generation of JS-MDS cascade reservoirs.

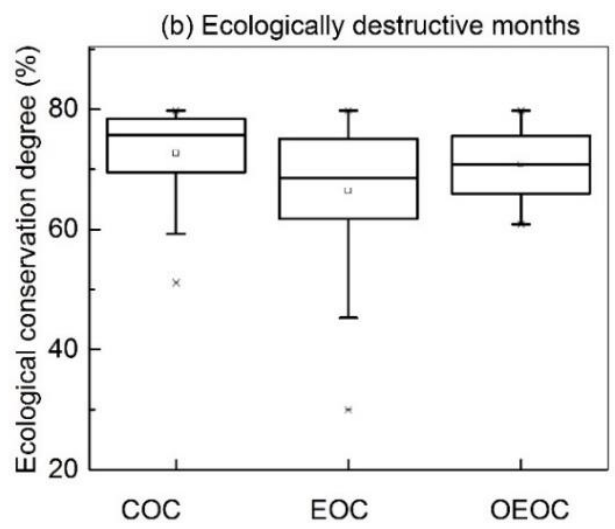

Figure 8. Ecological conservation degrees of the JS reservoir during different period: (a) Whole time period; (b) Ecologically destructive months.

(a) Whole time period

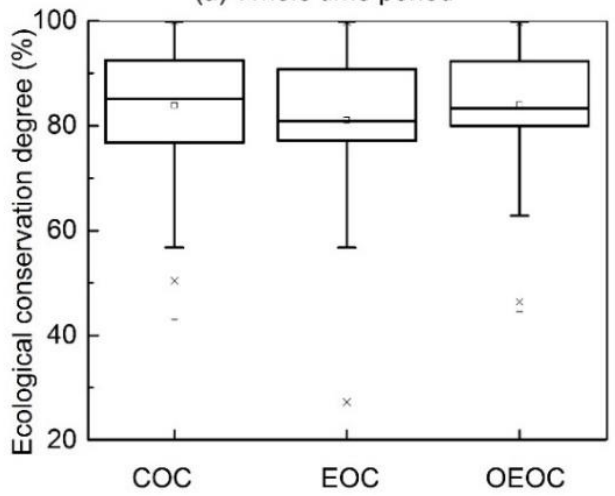

(b) Ecologically destructive months

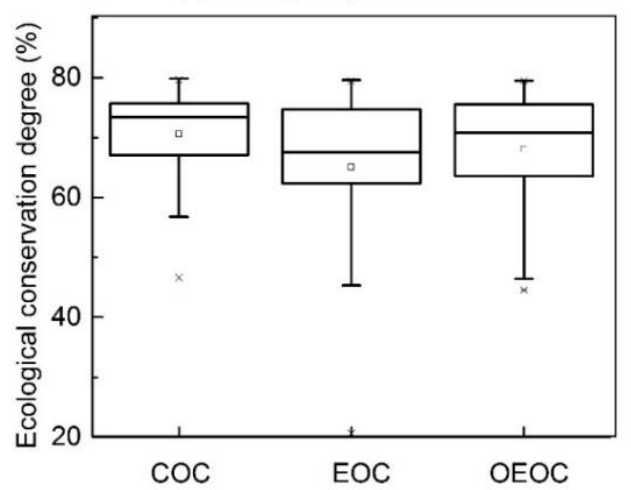

Figure 9. Ecological conservation degrees of the MDS reservoir during different period: (a) Whole time period; (b) Ecologically destructive months. 


\section{(2) Ecological conservation degree}

Under EOC, increasing the ecological target results in a decrease in the ecological conservation degree and ecological damage frequency of JS-MDS cascade reservoirs. The average ecological conservation degree of JS Reservoir is more severely decreased than that of MDS Reservoir, which is probably attributed to the higher adaptability of B. rutilus at the downstream of MDS Reservoir. For instance, at a $80 \%$ ecological target, the average ecological discharge range is $\left[188 \mathrm{~m}^{3} / \mathrm{s}, 746\right.$ $\mathrm{m}^{3} / \mathrm{s}$ ] and only [ $\left.57 \mathrm{~m}^{3} / \mathrm{s}, 339 \mathrm{~m}^{3} / \mathrm{s}\right]$ at the downstream of MDS and JS reservoirs, respectively.

Under OEOC, the ecological damage frequency of JS Reservoir, MDS Reservoir and JS-MDS cascade reservoirs is reduced compared with that under EOC. As Cyprinus rubrofuscus Lacépède and B. rutilus have a low requirement for ecological flow at an ecological target of $60 \%$ and $70 \%$, EOC is sufficient to reduce the ecological damage. In this case, there is no room for OEOC to further improve the ecological benefit. At a $80 \%$ ecological target, the fixed output zone overlapped with the limited ecological zone increases due to the decrease in the ecological discharge range and the increase in the minimum ecological discharge, which can reduce the ecological damage frequency and meanwhile have a notable effect on the overall ecological benefits. EOC can significantly decrease the average ecological conservation degree, but it is not effective enough to improve the ecological damage frequency. The average ecological conservation degree under OEOC is similar to that under COC, but the ecological damage frequency of JS and MDS reservoirs is significantly reduced by $74.0 \%$ and $43.8 \%$, respectively. At a $90 \%$ ecological target, both EOC and OEOC perform poorly in ecological conservation. Thus, the ecological requirement at a $90 \%$ ecological target may be too high to be achieved for JS and MDS reservoirs under OEOC and EOC.
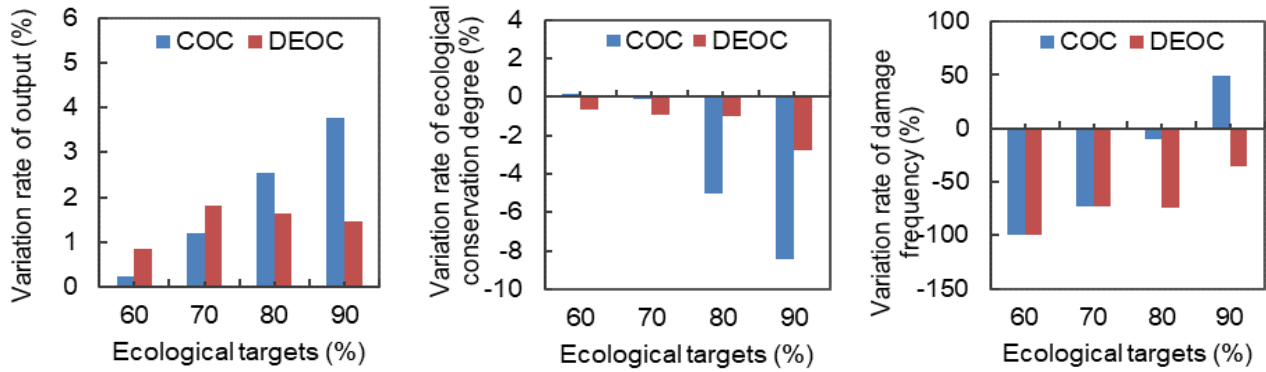

Figure 10. The variation rate of output, ecological conservation degree and ecological damage frequency of JS Reservoir under EOC and OEOC at different ecological targets.
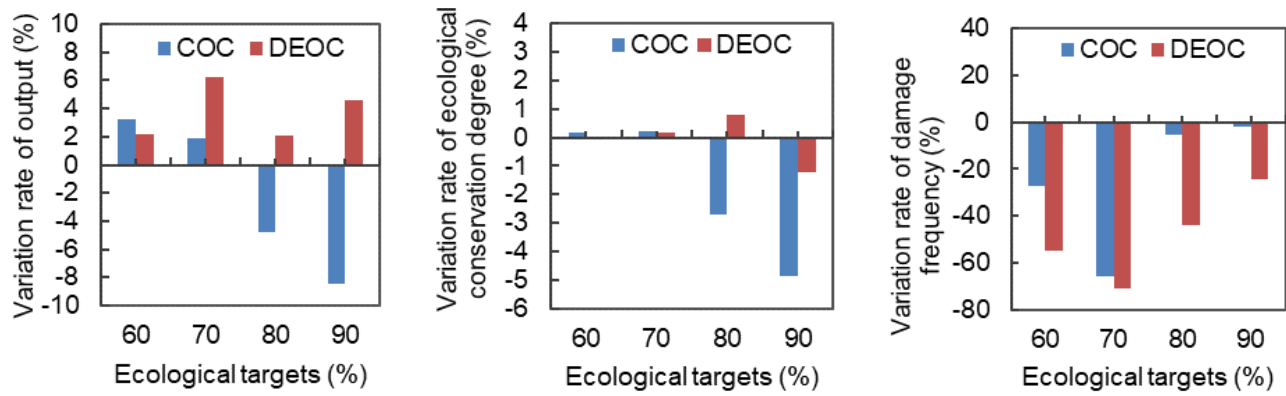

Figure 11. The variation rate of output, ecological conservation degree and ecological damage frequency of MDS Reservoir under EOC and OEOC at different ecological targets.
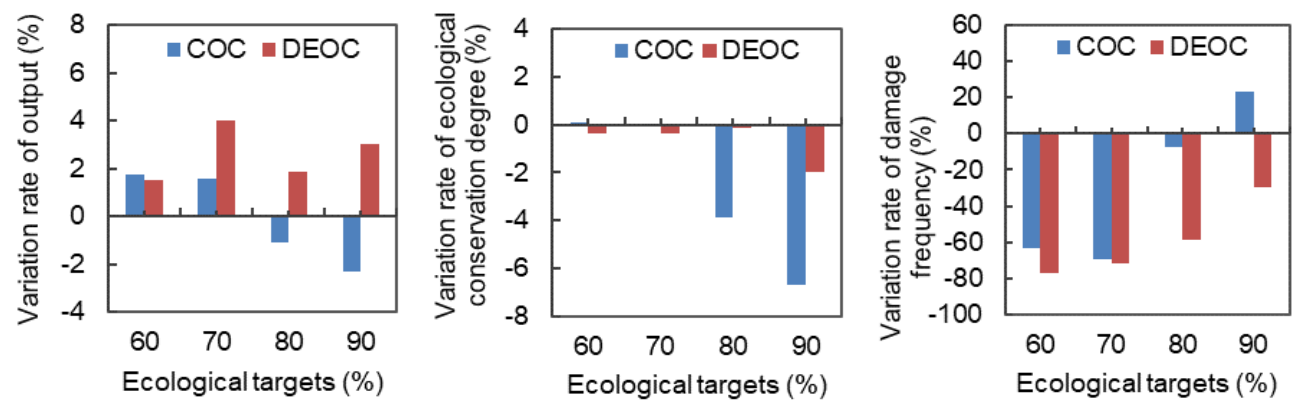

Figure 12. The variation rate of output, ecological conservation degree and ecological damage frequency of JS-MDS cascade reservoirs under EOC and OEOC at different ecological targets. 
In general, EOC results in an increase in ecological benefit and power generation of both JS and MDS reservoirs at an ecological target of $60 \%$ and $70 \%$, but a decrease in ecological benefit at an ecological target higher than $80 \%$. However, OEOC can result in satisfactory ecological benefit and power generation even at an ecological target higher than $80 \%$.

\section{Discussion}

Reservoir ecological operation has been a subject of considerable interest in recent years. It is clear that both long- and short-term ecological requirements should be considered in evaluating the ecological operation of cascade reservoirs. In the literature, the ecological requirement of a river basin is taken either as a constraint or as an objective to be optimized in the reservoir operation model. However, there is evidence that reservoir operation, whose objective is to maximize power generation, flood control or other objective with the minimum or appropriate ecological flow as the constraint, can only guarantee the basic ecological requirement of the river basin downstream of the reservoir (Sale et al., 1982; Yeh and Becker, 1982; Chen et al., 2015). In comparison, the incorporation of upper and lower limited ecological curves into OEOC in this study makes it possible to adjust the release to the upper and lower limit of the ecological discharge range in wet and dry years in order to strike a balance between hydrological extreme pressure and ecological requirements.

The average ecological requirements over a long period of time can also be taken as the objective to be optimized, which however may lead to the possibility that the ecological damage caused by flood or drought events in a given period is often overlooked or averaged out (Szemis et al., 2012). In this study, we have proposed an operation chart to balance long- and short-term ecological benefits. With the goal of minimizing the ecological damage frequency, the limited ecological curves were optimized under the constraints of the overall ecological profit determined by the reduction coefficients $\gamma$. Priority was also given to the overall ecological requirements in some previous studies. Chen et al., (2012) used the flow alternation degree instead of the ecological hydrograph to measure the differrence between regulated discharge and natural flow, which enabled the actual discharge to follow the natural flow as much as possible at an expense of a significant $(26.4 \%)$ loss of socialeco-nomic benefit. In order to mitigate potential impacts on power generation due to the optimization of ecological requirements, the minimum power generation is constrained in the optimized limited ecological curves of OEOC, making it possible to in-crease the ecological profit without significantly affecting power generation, and as a result the generation reduction coefficients $\beta$ can be adjusted more flexibly according to the power generation requirements and the ecological profit.

Both long-term average and short-term ecological benefits are incorporated in OEOC, making it possible to effectively reduce the ecological damage frequency while maintaining general ecological benefit. Another important advantage is that the operation policy could be adaptively adjusted by determining appropriate ecological targets and other parameters according to actual situation, also the operation rules can be changed based on the preference and experiences of decision makers.

\section{Conclusions}

This study proposed a new hydropower-ecological operation chart of cascade hydropower stations, in which limited ecological curves were introduced and optimized to alleviate the negative impacts caused by drought or flood events on fish habitat and to maintain the long-term average fish habitat quality without reducing power generation. PHABSIM was used to quantify the hydrological requirement and determine the optimal ecological flow range of the target fish species at different life stages. The limited ecological curves were derived and further optimized with the goal of reducing the ecological damage frequency as much as possible in hydrological extremes. A case study was performed with JS and MDS reservoirs on the Yuan River in southwestern China. The main conclusions can be summarized as follows:

The EOC that takes into account the ecological benefit can reduce the ecological damage frequency compared to the COC, but potentially at the expense of the overall ecological benefit. However, further optimization of the limited ecological curves in OEOC results in higher short-term ecological benefit and lower ecological damage frequency in flood or drought extremes with less loss of the overall ecological benefit. In cascade reservoir operation, it is necessary to flexibly adjust the ecological conservation degrees and weights of different objectives, so that an appropriate OEOC can be obtained for different conditions.

For JS and MDS reservoirs, OEOC can result in higher ecological and power generation benefit than EOC and COC at an ecological target of $60 \sim 80 \%$. Despite the slight decrease (approximately 1\%) in ecological conservation degree of JS Reservoir, the ecological damage frequency is significantly reduced by approximately $70 \sim 100 \%$. In particular, at an ecological target of $80 \%$, OEOC results in a $4.1 \%$ increase in power generation and a $11.25 \%$ decrease in ecological damage frequency for JS-MDS cascade reservoirs compared with that of COC, respectively.

The reservoir operation chart proposed in this study has focused on the balance between the long- and short-term ecological benefit, especially the ecological damage frequency. However, it is important to note that the ecological damage magnitude is also important in short-term ecological requirement, and thus further studies are needed to elucidate how to balance ecological damage magnitude, ecological damage frequency and the overall ecological benefit. With the improvement of hydrological prediction accuracy, there is also a need to incorporate multi-scale hydrological forecast information into the optimized reservoir operation chart.

Acknowledgments. This research is funded by National Natural Science Foundation of China (U1765201), the Fundamental Research Funds for the Central Universities (2018B11314), CRSRI Open Research Program (CKWV2016370/KY). 


\section{References}

Booker, D.J., and Acreman, M.C., (2007). Generalisation of physical habitat-discharge relationships. Hydrol. Earth Syst. Sci., 11, 141157. https://doi.org/10.5194/hess-11-141-2007

Bovee, K.D. (1986). Development of Habitat Suitability Criteria for Use in the Instream Flow Incremental Methodology. Usgs Fort Collins Science Center 86.

Bovee, K.D., and Milhous, R.T. (1978). Hydraulic Simulation in Instream Flow Studies: Theory and Techniques. Page 130 Instream Flow Information Paper 5. U.S. Fish \& Wildlife Service Biological Report.

Chang, J.X., Meng, X.J., Wang, Z.Z., Wang, X.B., and Huang, Q. (2014). Optimized cascade reservoir operation considering ice flood control and power generation. J. Hydrol., 519, 1042-1051. https:// doi.org/10.1016/j.jhydrol.2014.08.036

Chen, D., Li, R.N., Chen, Q.W., and Cai, D.S. (2015). Deriving optimal daily reservoir operation scheme with consideration of downstream ecological hydrograph through a time-nested approach Water Resour. Manag., 29, 3371-3386. https://doi.org/10.1007/s11 269-015-1005-Z

Chen, Q., Chen, D., Li, R., Ma, J., and Blanckaert., K. (2013). Adapting the operation of two cascaded reservoirs for ecological flow requirement of a de-watered river channel due to diversiontype hydropower stations. Ecol. Modell., 252, 266-272. https://doi. org/10.1016/j.ecolmodel.2012.03.008

Chen, Q.W., Chen, D., Han, R.G., Li, R.N., Ma, J.F., and Blanckaert, K. (2012). Optimizing the operation of the Qingshitan Reservoir in the Lijiang River for multiple human interests and quasi-natural flow maintenance (China). J. Environ. Sci., 24, 1923-1928. https:// doi.org/10.1016/S1001- 0742(11)61029-2

Cheng, C., Yang, F., Wu, X., and Su, H. (2010). Link the simulation with dynamic programming successive approximations to the study on optimal operation chart of cascade reservoirs. J. Hydroel. Eng., 29, 71-77

Gibbins, C.N., Soulsby, C., Jeffries, M.J., and Acornley, R. (2001). Developing ecologically acceptable river flow regimes: a case study of Kielder reservoir and the Kielder water transfer system. Fish. Manag. Ecol., 8, 463-485. https://doi.org/10.1046/j.13652400.2001. 00274.x

He, D., Wu, R., Feng, Y., Li, Y., Ding, C., Wang, W., and Yu, D.W. (2014). China's transboundary waters: new paradigms for water and ecological security through applied ecology. J. Appl. Ecol., 51, 1159-1168. https://doi.org/10.1111/1365-Of2664.12298

Jiang, Z., Ji, C., Sun, P., Wang, L., and Zhang, Y. (2014). Total output operation chart optimization of cascade reservoirs and its application. Energ. Convers. Manag. 88, 296-306. https://doi.org/10.1016/j. enconman.2014.08.043

Jiang, Z., Li, A., Ji, C., Qin, H., Yu, S., and Li, Y. (2016). Research and application of key technologies in drawing energy storage operation chart by discriminant coefficient method. Energ. 114, 774-786. ht tps://doi.org/10.1016/j.energy.2016.08.043

Larson, R.E. and Korsak, A.J. (1970). A dynamic programming successive approximations technique with convergence proofs. $\mathrm{Au}$ tomatica, 6, 245-252. https://doi.org/10.1016/0005-1098(70)900 95-6

Li, W.M., Chen, Q.W., Cai, D.S., and Li, R.N. (2015). Determination of an appropriate ecological hydrograph for a rare fish species using an improved fish habitat suitability model introducing landscape ecology index. Ecol. Modell., 311, 31-38. https://doi.org/10.1016/j. ecolmodel.2015.05.009

Mei, Y.D., Yang, N., and Zhai, L.N. (2009). Optimal ecological sound operation of the cascade reservoirs in the lower Yalongjiang River (in Chinese). Adv. Water Sci., 20, 721-725.

Opan, M. (2010). Irrigation-energy management using a DPSA-based optimization model in the Ceyhan Basin of Turkey. J. Hydrol., 385, 353-360. https://doi.org/10.1016/j.jh ydrol.2010.03.003

Rossel, V., and de la Fuente, A. (2015). Assessing the link between environmental flow, hydropeaking operation and water quality of reservoirs. Ecol. Eng., 85, 26-38. https://doi.org/10.1016/j.ecoleng. 2015.09.074

Sale, M.J., Jr, E.D.B., and Herricks, E.E. (1982). An approach to optimizing reservoir operation for downstream aquatic resources. Water Resour. Resear., 18, 705-712. https://doi.org/10.1029/WR 018i004p00705

Shi, Z., Cheng, J., Yang, S., Chang, B., and Jiang, Y. (2015). Research on Methods of Optimal Water Resources Allocation for Single Reservoir-Single Pump StationSystem Using DPSA. J. Irrig. Drain., 34, 37-40.

Suen, J.P., and Eheart. J.W. (2006). Reservoir management to balance ecosystem and human needs: Incorporating the paradigm of the ecological flow regime. Water Resour. Resear., 42. https://doi.org/ 10.1029/2005WR004314

Szemis, J.M., Maier, H.R., and Dandy, G.C. (2012). A framework for using ant colony optimization to schedule environmental flow management alternatives for rivers, wetlands, and floodplains. Water Resour. Resear., 48. https://doi.org/10.1029/2011WR011276

Taghian, M., Rosbjerg, D., Haghighi, A., and Madsen, H. (2014). Optimization of conventional rule curves coupled with hedging rules for reservoir operation. J. Water Resour. Plann. Manag., 140, 693698. https://doi.org/10.1061/(ASCE)WR.1943-5452.0000355

Tan, Q.F., Wang, X., Wang, H., Wang, C., Lei, X.H., Xiong, Y.S. and Zhang, W. (2017). Derivation of optimal joint operating rules for multi-purpose multi-reservoir water-supply system. J. Hydrol. 551, 253-264. https://doi.org/10.1016/j.jhydrol.2017.06.009

Tharme, R.E. (2003). A global perspective on environmental flow assessment: Emerging trends in the development and application of environmental flow methodologies for rivers. River Res. Appl., 19, 397-441. https://doi.org/10.1002/rra.736

Waddle, T. (2001). PHABSIM for Windows User's Manual and Exercises. https://doi.org/10.3133/ofr2001340

Wang, C. (2017). Research conception of ecological protection and restoration of high dams and large reservoirs construction and hydro-power cascade development in Southwestern China. Adv. Eng. Sci., 49, 19-26.

Wen, X., Fang, G.H., Guo, Y.X., and Zhou. L. (2016). Adapting the operation of cascaded reservoirs on Yuan River for fish habitat conservation. Ecol. Modell., 337, 221-230. https://doi.org/10.1016/j. ecolmodel.2016.06.018

Wilding, T.K., Bledsoe, B., Poff, N.L., and Sanderson, J. (2014). Predicting habitat response to flow using generalized habitat models for trout in rocky mountain streams. River Res. Appl. 30, 805-824. https://doi.org/10.1002/rra.2678

Yang, N., Mei, Y.D., and Zhou. C. (2012). An Optimal Reservoir Operation Model Based on Ecological Requirement and Its Effect on Electricity Generation. Water Res. Manag., 26, 4019-4028. https: //doi.org/10.1007/s11269-012-0126-x

Yeh, W.W.G. and Becker, L. (1982). Multiobjective analysis of multireservoir operations. Water Resour. Res., 18, 1326-1336. https:// doi.org/10.1029/WR018i005p01326

Yi, J., Labadie, J.W. and Stitt, S. (2003). Dynamic optimal unit commitment and loading in hydropower systems. J. Water Resour. Plann. Manag., 129, 388-398. https://doi.org/10.1061/(ASCE)0733 9496(2003)129:5(388)

Yin, X.A., and Yang, Z.F. (2011). Development of a coupled reservoir operation and water diversion model: Balancing human and environmental flow requirements. Ecol. Modell., 222, 224-231. https:// doi.org/10.1016/j.ecolmodel.2010.06.025

Zahraie, B. and Hossein, S.M. (2009). Development of reservoir operation policies considering variable agricultural water demands. Expert Syst. Appl., 36, 4980-4987. https://doi.org/10.1016/j.eswa. 2008.06.135

Zhou, Y., and Guo, S. (2013). Incorporating ecological requirement into multipurpose reservoir operating rule curves for adaptation to climate change. J. Hydrol., 498, 153-164. https://doi.org/10.1016/j. jhydrol.2013.06.028 